\title{
Gene flow from transgenic common beans expressing the bar gene
}

\author{
Josias C. Faria, ${ }^{1, *}$ Geraldo E.S. Carneiro² and Francisco J.L. Aragão ${ }^{3}$ \\ 'Embrapa Arroz e Feijão; Santo Antônio de Goiás; Goiás, Brazil; ${ }^{2}$ Embrapa Soja; Londrina, Paraná Brazil; ${ }^{3}$ Embrapa Recursos Genéticos e Biotecnologia; Brasília, DF Brazil
}

Key words: Phaseolus vulgaris, outcross, glufosinate ammonium

\begin{abstract}
Gene flow is a common phenomenon even in self-pollinated plant species. With the advent of genetically modified plants this subject has become of the utmost importance due to the need for controlling the spread of transgenes. This study was conducted to determine the occurrence and intensity of outcrossing in transgenic common beans. In order to evaluate the outcross rates, four experiments were conducted in Santo Antonio de Goiás (GO, Brazil) and one in Londrina (PR, Brazil), using transgenic cultivars resistant to the herbicide glufosinate ammonium and their conventional counterparts as recipients of the transgene. Experiments with $\mathrm{cv}$. Olathe pinto and the transgenic line Olathe M1/4 were conducted in a completely randomized design with ten replications for three years in one location, whereas the experiments with cv. Pérola and the transgenic line Pérola M1/4 were conducted at two locations for one year, with the transgenic cultivar surrounded on all sides by the conventional counterpart. The outcross occurred at a negligible rate of $0.00741 \%$ in cv. Pérola, while none was observed $(0.0 \%)$ in cv. Olathe pinto. The frequency of gene flow was cultivar dependent and most of the observed outcross was within $2.5 \mathrm{~m}$ from the edge of the pollen source.
\end{abstract}

\section{Introduction}

Common bean (Phaseolus vulgaris L.) is a predominantly selfpollinated species, which was domesticated some 10,000 years ago. ${ }^{1}$ Domestication primarily included selection for reduced seed dispersal and dormancy, a more compact growth habit, reduced sensitivity to day length and tendency towards increased selfing or vegetative propagation, and an increase in diversity and size of the harvested parts. ${ }^{2}$ Domestication was mainly from the Mesoamerican and Andean gene-pools. ${ }^{3}$ According to Rieger et $\mathrm{al}^{4}{ }^{4}$ gene flow is the dissemination, transfer or establishment of genes or alleles from one population to another of the same species due to the dispersion of gametes or zygotes. The outcrossing rates are highly variable, varying from 0.0 to $66.8 \%$ within $P$. vulgaris, depending also on the varieties evaluated. ${ }^{5-7}$ As noted by Bliss, ${ }^{8}$ the common bean flower structure has a typical legume shape. The corolla has two petals which are fused forming a prolonged keel, two wing petals and a standard. The keel encloses one free and nine fused stamens; each has a bilobed anther sac borne on a long filament. The pistil has an ovary containing 5 to 8 or up to 10 ovules. The style is coiled and the stigma is a slightly flattened pad with hairs. The stamen filaments follow the stylar coil in such a way that the anther sacs are appressed to the stigma. Pollen grains shed directly onto the stigmatic surface, resulting in self-pollination. This type of structure leads us to consider beans as a cleistogamic species. In spite of this fact, different outcrossing rates that have consequences for breeding and maintenance of the genetic purity of certified seeds have been reported in the literature. Several of the studies were carried out under conditions which are not typical of an agricultural system, such as lack of inter-row spacing. ${ }^{6,7}$ Evaluation of outcross rate has essentially been done on the basis of pigmentation traits being dominant over non-pigmentation, such as color of flowers and color of the epicotyls. The difficulties associated with the use of these characteristics and also of molecular markers have prevented scientists from studying outcross rates on a larger scale. Traditionally, gene flow has been seen as a factor of evolution. However, the advent of genetically modified organisms (GMOs), and consequently the possibility of the spread of transgenes to wild and domesticated relatives, has raised a new set of issues to be considered by scientists and policymakers. The phenomenon can occur via pollen, seeds, or vegetative propagules, but pollen is seen as the most important pathway in transgene dispersal.

One of the biosafety questions posed by regulators is related to the ability of gene dispersal from the transgenic variety through pollen and its potential impact.' Strict law regulations on the presence of transgenes leads to rigorous seed purity requirements and purity of the commercialized grain eventually harvested. As $\mathrm{Tait}^{10}$ has pointed out, the regulatory processes may vary among countries, with the European system being the most stringent. However, GMOs which have been released based on a much less demanding regulatory system are utilized as food and are consumed on a daily basis by millions of people. In fact the cultivated area with GMOs in Brazil grew by $30 \%$ in the consecutive years of 2006 and 2007, as noted by James, ${ }^{11,12}$ with a tendency to a faster rate of adoption due to the 
Table 1. Evaluation of plants to verify the presence of gene flow in common beans

\begin{tabular}{|cccc|}
\hline Cultivar/year & $\begin{array}{c}\text { No. of } \\
\text { plants } \\
\text { evaluated }\end{array}$ & $\begin{array}{c}\text { No. of survived } \\
\text { plants after } \\
\text { herbicide } \\
\text { application }\end{array}$ & $\begin{array}{c}\text { Frequency } \\
\text { of gene } \\
\text { flow }\end{array}$ \\
\hline Olathe pinto/2004 & 36,025 & 0 & Negative \\
\hline Olathe pinto/2005 & 37,156 & 0 & Negative \\
\hline Olathe pinto/2006 & 10,489 & 0 & Negative \\
\hline $\begin{array}{c}\text { Olathe pinto/Total } \\
\text { Pérola in Santo Antônio } \\
\text { de Goiás, GO/2006 }\end{array}$ & 83,630 & 0 & Negative \\
\hline $\begin{array}{c}\text { Pérola in Londrina, } \\
\text { PR/2006 }\end{array}$ & 21,709 & 7 & $0.0070 \%$ \\
\hline Pérola/Total & 121,447 & 9 & $0.0092 \%$ \\
\hline
\end{tabular}

2009 commercial releases authorized by the Brazilian Biosafety Commission (CTNBio).

There is lack of knowledge on cross-pollination in common bean between a transgenic and a conventional cultivar in the breeding plots. The objective of the present work was to analyze the outcrossing rate in common bean using a herbicide-resistant transgenic line. In this paper gene flow is reported exclusively as a pollen-mediated phenomenon, in different geographic environments and across years.

\section{Results and Discussion}

A total of 83,630 seedlings derived from the seeds collected from cv. Olathe Pinto grown in the experiments during the three years were evaluated for herbicide resistance (Table 1). No seedling resistant to glufosinate ammonium was found. The herbicidesprayed control rows of Olathe Pinto were completely killed while those of transgenic line Olathe M1/4 remained symptomless. Therefore it was concluded that there was no detectable gene flow from line Olathe M1/4 to cv. Olathe Pinto under the threeyear experimental conditions.

Total seed collected from cv. Pérola was cultivated and resulted in 121,447 plants which were scored for resistance to glufosinate ammonium (Table 1). Nine putative herbicide resistant seedlings were identified. No plants from the control rows planted with $\mathrm{cv}$. Pérola escaped from the herbicide treatment (Fig. 2A), while all plants from the line Pérola M1/4 remained undamaged (Fig. 2B).

The nine $\mathrm{F}_{1}$ plants remaining from the experiment were carefully transplanted to pots and transferred to the greenhouse to produce seeds which were harvested and kept separately for each plant. The analyses of the offspring $\left(\mathrm{F}_{2}\right.$ generation) by PCR and by the leaf painting test with glufosinate ammonium showed clear segregation among the offsprings. The overall distribution of the $\mathrm{F}_{2}$ plants into resistant/susceptible to herbicide fits the 3:1 proportion, expected for a single gene inheritance, based on the chi-square test (Table 2). Immunological analyses using the LL Test Kit confirmed the presence of the PAT protein in transgenic plants. Thus, it was concluded that the nine parental $\left(\mathrm{F}_{1}\right)$ plants originated from pollen flow rather than by seed mixture.
The gene flow rate was cultivar dependent, confirming early observations of Wells ${ }^{7}$ who clearly indicated the effect of variety on the observed outcross rate. After three years of experiments, no outcrossing was identified in cv. Olathe Pinto, while it was observed in cv. Pérola at both experimental sites. The approximate rates of outcrossing were proportionally the same for both locations, considering the sample size. Every greenhousetransplanted putative transgenic seedling resulted in progenies with segregation, indicating that the putative transgenic plants were the result of pollen flow. Outcrossing was observed up to $6.5 \mathrm{~m}$ from the nearest source, with the highest incidence at 1 $\mathrm{m}$. There was no prevailing direction to assign the resulting outcross, for Santo Antônio de Goiás (GO) experiment since four plants were to the South and three plants to the North; for the Londrina (PR) location, both plants came from the West.

Webster et al. ${ }^{14}$ conducted a morphological study of reproductive structures of Phaseolus vulgaris using scanning electron microscopy. They indicated that at anthesis the stigma is partly dry and therefore receptivity to pollen is negligible. This is in accordance with our findings of extremely low outcross rate. However, other authors ${ }^{5,15}$ have indicated that the presence and size of pollinator bees may have important considerations as well. As discussed by Webster et al. ${ }^{14}$ to be successful in carrying out crosspollination an insect must acquire the pollen from one flower and move to a receptive flower where it should perforate the wings, before anthesis, to leave the pollen on the receptive stigmatic surface. Besides, the role of bees and bumble bees is somewhat problematic. The weight of a bee on wing or keel petals resulted in pistil movement and effective self-pollination. These studies led to the concept that common bean is a cleistogamic species.

The data presented in this paper are within the low range of outcrossing published in recent years for common beans. Ferreira et al. ${ }^{5}$ found a gene flow rate ranging from $0.0045 \%$ to $0.136 \%$. In the past, Tucker and Harding ${ }^{6}$ evaluated outcrossing using six varieties. Twenty-thousand progenies were scored with no outcross observed. Gene flow among plants within a given line is not considered important from the viewpoint of seed purity, interplot contamination or even transgene flow, since common bean is bred as pure line.

While there was no single factor which could account for promotion of outcrossing, the result is relevant to the biosafety of transgenic common bean. Current Brazilian regulations for conventional common bean seed production require $3 \mathrm{~m}$ of isolation between fields of different varieties to maintain seed purity. Regarding GMOs, The Brazilian law requires that traces of genetically modified organisms should be less than $1 \%$ in any processed food. Estimation of gene flow from crop to wild relatives is not within the scope of this paper, since Brazil is not a center of origin and typically does not grow landraces in large areas.

Gene flow can be avoided by planting varieties differing in flowering time or planting dates to avoid simultaneous flowering. From a biosafety point of view the average rate of $0.00741 \%$ outcross would indicate that there is no need to isolate transgenic commom bean fields. However, since gene flow could be detected up to $6.5 \mathrm{~m}$, an isolation of a transgenic field from another field 
Table 2. $F_{2}$ progeny from $F_{1}$ plants possibly resulting from gene flow

\begin{tabular}{|c|c|c|c|c|c|}
\hline $\begin{array}{l}\text { Putative transgenic plants and } \\
\text { the location }{ }^{(1)}\end{array}$ & Plants evaluated & $\begin{array}{l}\text { Herbicide } \\
\text { resistant }\end{array}$ & $\begin{array}{c}\text { Herbicide } \\
\text { susceptible }^{(\mathfrak{b})}\end{array}$ & $\begin{array}{l}\mathrm{X}^{2} \text { analysis/ } \\
\text { probability }\end{array}$ & $\begin{array}{c}\text { No. plants } \\
\text { evaluated by } P C R^{(c)}\end{array}$ \\
\hline $39 \mathrm{G}-\mathrm{GO}$ & 37 & 28 & 9 & $0.01(0.92)$ & 5 \\
\hline $15 \mathrm{E}-\mathrm{GO}$ & 29 & 21 & 8 & $0.10(0.75)$ & 2 \\
\hline $47 \mathrm{C}-\mathrm{GO}$ & 2 & 2 & 0 & $0.67(0.41)$ & - \\
\hline $25 \mathrm{G}-\mathrm{GO}$ & 3 & 2 & 1 & $0.11(0.74)$ & - \\
\hline $20 \mathrm{G}-\mathrm{GO}$ & 3 & 3 & 0 & $1.00(0.32)$ & - \\
\hline $12 \mathrm{E}-\mathrm{PR}$ & 21 & 15 & 6 & $0.14(0.71)$ & 3 \\
\hline $13 C-P R$ & 24 & 18 & 6 & $0.00(1.00)$ & 3 \\
\hline Pérola M1/4 & 13 & 13 & 0 & & 1 \\
\hline
\end{tabular}

${ }^{(1)} \mathrm{GO}$, denotes plants from Goiás; PR, denotes plants from Paraná; (b)The observed ratio of herbicide-resistant: susceptible fits the expected value of 3:1 for a monogenic trait; ${ }^{(c)}$ All of the herbicide-resistant plants evaluated by PCR were positive '-' a dash means that no plant was evaluated.

by $10.0 \mathrm{~m}$ would be sufficient to maintain seed purity and avoid the possibility of outcrossing, because most of this small value of gene flow came from the nearest distance of $2.5 \mathrm{~m}$. Wind direction did not play a role in pollen dissemination in the current study.

The opportunity for the transgene to escape via hybridization depends on the presence of the wild type or closely related species able to cross under a natural ecosystem. Undoubtedly the marked presence of cleistogamy and the absence of closely related relatives in the growing region (outside the center of origin) makes the transfer of the transgene unlikely or with a very low incidence in the case of common beans in Brazil. This does not necessarily mean that it will not occur, but this study clearly indicated that its occurrence and importance may be minimized if adequate isolation is maintained.

\section{Materials and Methods}

The transgenic bean line Olathe M1/4 incorporating the bar gene, encoding phosphinothricin acetyltransferase (PAT), which confers tolerance to the herbicide glufosinate ammonium, has been previously described. ${ }^{13}$ This unique characteristic was used to study gene flow to original conventional cv. Olathe Pinto, since they exactly match each other in growth cycle, thus theoretically favoring gene flow. In addition, the transgene has been transferred to the commercial cv. Pérola through four backcrosses, thus recovering over $95 \%$ of the genetic background of the commercial cultivar. Gene flow experiments using commercial cv. Pérola and its transgenic counterpart, near isogenic line Pérola M1/4, were also conducted. All experiments were authorized by the Brazilian Biosafety Commission.

Experimental trials which included the conventional $\mathrm{cv}$. Olathe Pinto and transgenic line Olathe M1/4 were conducted in three consecutive years, from 2004 to 2006. The layout was a completely randomized design with ten replications. Each plot

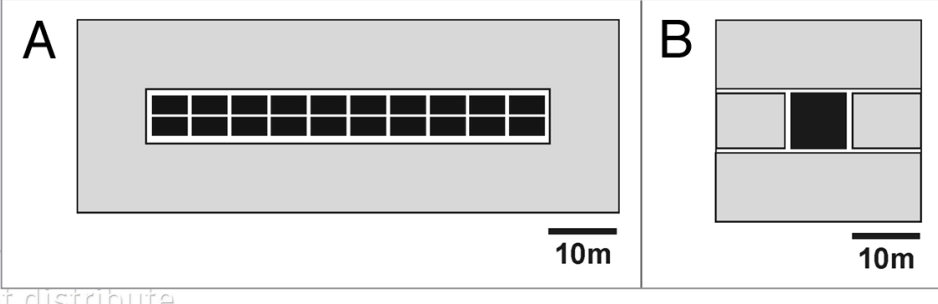

Figure 1. Diagram of the field design for experiments conducted from 2004 to 2006 to study gene flow in genetically modified common bean. Nontransgenic plants (in gray) of cv. Olathe Pinto (A) and cv. Pérola (B) were sown surrounding a central plot (in black) cultivated with the transgenic line Olathe M1/4 and Olathe Pinto (A) and the near isogenic line Pérola M1/4 (B).

consisted of five rows of $5.0 \mathrm{~m}$ long spaced $0.5 \mathrm{~m}$ apart. Twenty rows were sown surrounding the experiment with cv. Olathe Pinto for sampling gene flow in a $10.0 \mathrm{~m}$ wide area around the transgenic plots (Fig. 1A). Fifteen seeds were sown per meter and later thinned to 12 plants per meter. Flowering date occurred at 28-32 days after seeding for both germplasms in all three experiments. All agronomic practices were followed according to the standard recommendations. Pest control was done whenever necessary, using principles of integrated pest management. Three meter-rows were marked from each one of the twenty border rows on either side of the experiment and on the edges totaling 420 samples per experiment. All seeds from these samples, as well as a sample from each of the 10 non-transgenic plots, were used to evaluate gene flow.

The two experimental plots using cv. Pérola and the transgenic near isogenic line Pérola M1/4 consisted of a central square of $8 \mathrm{~m}$, which was sown with the transgenic isoline and a 10-meter border on all sides (enough for 20 rows) seeded with conventional cv. Pérola (Fig. 1B). Row spacing was kept at $0.5 \mathrm{~m}$, and seed density at planting time was at the rate of 15 seeds per linear meter. The experiment was conducted in Santo Antônio 

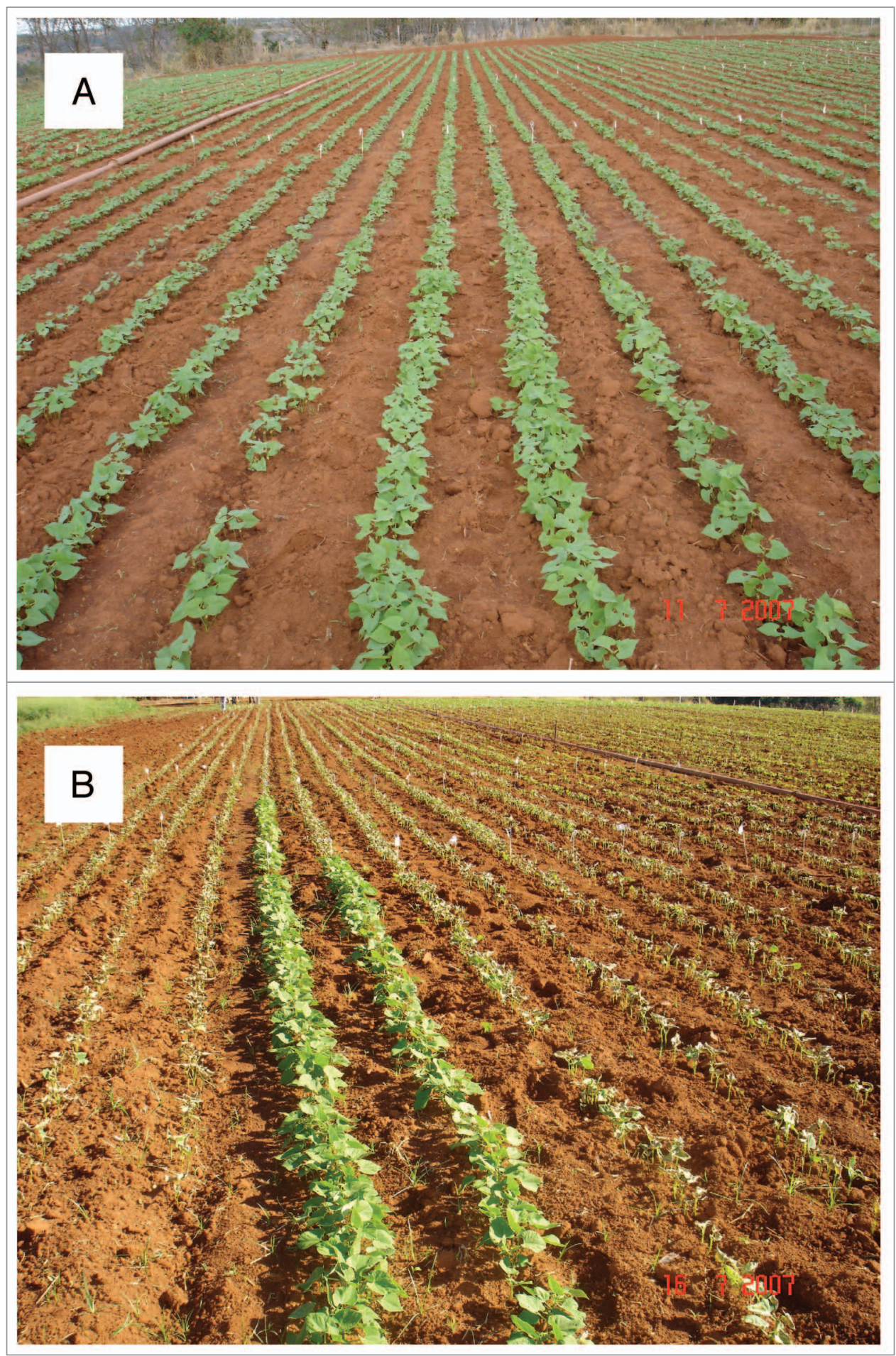

Figure 2. Partial view of the common bean experiment to evaluate seeds harvested from the five experiments for gene flow. (A) Field grown plants before herbicide application; (B) detailed view of the herbicide-resistant Pérola M1/4 control rows at the center.

de Goiás, GO (Latitude S. $16^{\circ} 28^{\prime}$, Longitude $W 4^{\circ} 17^{\prime}$ ) and Londrina, PR (Latitude S $23^{\circ} 10^{\prime}$, Longitude W $51^{\circ} 10^{\prime}$ ), in Brazil in 2006. Flowering date occurred at 42-45 days after seeding for both germplasms in all three experiments. At both locations, three meter-rows were marked from each one of the twenty border rows on either side of the experiment and on the edges totaling
352 samples per experiment. All seeds from these samples were used to evaluate gene flow.

All collected seeds, from the five experiments, were sown in the field at Santo Antônio de Goiás, GO in 2007 and sprayed at the seedling stage to test for resistance to glufosinate ammonium, using a concentration of $0.03 \%$ active ingredient, enough to kill 
the conventional bean seedlings. The experimental rows were intercalated with $5 \mathrm{~m}$-rows of the parental transgenic lines and the susceptible control cvs. Olathe Pinto and Pérola. Remaining plants were further tested for herbicide resistance, due to irregular or non-synchronized germination, by spraying two more times. The plants that still survived were evaluated by PCR using specific primers ${ }^{13}$ to detect bar transgene, then transplanted to pots and taken to a greenhouse to complete their reproductive cycle. All plants were subjected to an additional herbicide treatment and PCR analysis.

A progeny test for the $\mathrm{F}_{2}$ generation obtained from seeds harvested from field-derived plants ( $F_{1}$ generation) was conducted in the greenhouse. The presence of segregation would indicate that the original plant was the result of gene flow while the lack of segregation would indicate a mechanical seed mixture. All resulting plants were subjected to a leaf painting test with glufosinate ammonium using the same rate of active ingredient as before. A leaf sample from some of the resistant plants was evaluated by specific PCR and the LL Test Kit (Strategic Diagnostics Inc., Newark, USA) to detect both bar transgene and PAT protein, respectively. Chi-square analyses were performed to determine whether or not the observed resistant:susceptible ratio was consistent with the Mendelian ratio of 3:1, with a $95 \%$ level of confidence. When appropriated, the correction factor of Yates was used.

\section{Acknowledgements}

The authors thank Vanderlino Moreira de Santana for technical support in the greenhouse and field. This work was partially supported by a grant from Financiadora de Estudos e Projetos-FINEP.

\section{References}

1. Gepts P. Ten thousand years of crop evolution. In: Chrispels MJ, Sadava DE, eds. Plants, Genes and Crop Biotechnology. $2^{\text {nd }}$ ed. Sudbury MA, USA: Jones and Bartlett Publishers 2000; 328-59.

2. Papa R, Acosta J, Delgado-Salinas A, Gepts P. A genome-wide analysis of differentiation between wild and domesticated Phaseolus vulgaris from Mesoamerica. Theor Appl Genet 2005; 111:1147-58.

3. Singh S, Gepts P, Debouck D. Races of common bean (Phaseolus vulgaris, Fabaceae). Econ Bot 1991; 45:37996.

4. Riege R, Michaelis A, Green MM. Glossary of genetic and cytogenetics-classical and molecular. $4^{\text {th }}$ ed. New York NY, USA: Springer-Verlag 1976; 647.

5. Ferreira JL, Carneiro JES, Teixeira AL, Lanes FF, Cecon PR, Borem A. Gene flow in common bean (Phaseolus vulgaris L.). Euphytica 2007; 153:165-70.
6. Tucker CL, Harding J. Outcrossing in common bean, Phaseolus vulgaris L. J Am Soc Hortic Sci 1975; 100:283-5.

7. Wells WC, Isom WH, Waines JG. Outcrossing rates of six common bean lines. Crop Sci 1988; 28:177-8.

8. Bliss FA. Common bean. In: Fehr WR, Hadley HH, eds. Hybridization of Crop Plants. Madison WI, USA American Society of Agronomy and Crop Science Society of America 1980; 273-84.

9. Ray JD, Kilen TC, Abel CA, Paris RL. Soybean natura cross-pollination rates under field conditions. Environ Biosafety Res 2003; 2:133-8.

10. Tait J. Risk governance of genetically modified cropsEuropean and American perspectives. In: Renn O, Walker K, eds. Global Risk Governance: Concept and Practice Using the IRGC Framework. Dordrecht, The Netherlands: Springer 2008; 133-53.
11. James C. Global Status of Commercialized Biotech/ GM Crops: 2008. ISAAA Brief No. 39. ISAAA: Ithaca NY, USA 2008.

12. James C. A global overview of biotech (GM) crops adoption, impact and future prospects. GM Crops 2010; 1:1-5.

13. Faria JC, Albino MMC, Dias BBA, Cançado LJ, Cunha NB, Silva LM, et al. Partial resistance to bean golden mosaic virus in a transgenic common bean (Phaseolus vulgaris) line expressing a mutant rep gene. Plant Sci 2006; 171:565-71.

14. Webster BD, Tucker CL, Lynch SP. A morphological study of the development of reproductive structures of Phaseolus vulgaris L. J Amer Soc Hort Sci 1977; 102:640-3.

15. Ramalho MAP, Santos JB. Melhoramento do feijāo. Inf Agropec 1982; 8:16-9 